\section{Worse with treatment: do not make these mistakes}

\section{N. Sydney Moise}

During this presentation numerous examples of mistakes or adverse responses to medication will be shared. The purpose here is to explain how missteps came about and then how they were recognized. Examples of cases that will be illustrated include those in which excessive bradycardias occurred, complete cardiac arrest developed, renal failure developed and ventricular fibrillation resulted.

\section{KEY LEARNING OBJECTIVES}

- Learn to be conscientious in review when problems unexpectedly occur

- Review doses and the reasons for errors with colleagues

- Recognize when the drug may have been the problem

\section{MULTIPLE CHOICE QUESTIONS}

1. Which of the following scenarios indicates that the dose of pimobendan should be increased?
(A) Bradycardia
(B) Tachycardia
(C) Increased respiratory rate

(D) Decreased systolic pressure

2. The respiratory rate is increased and echocardiography shows large left atrium and dilated pulmonary veins with cardiomegaly in a dog with a grade 4 systolic murmur and degenerative mitral valve disease; however, the radiograph interpretation states cardiac enlargement but no pulmonary oedema. What is the best plan?
(A) No congestive heart failure is evident so treatment is not indicated
(B) Radiographs do not always reveal pulmonary oedema or it may be misinterpreted in elderly animals; therefore, treatment is instituted for cardiac failure
(C) Pimobendan alone is administered
(D) An angiotensin-converting enzyme inhibitor alone is administered

3. Which of the following is not an acceptable consequence of medication?
(A) More than two blocked $\mathrm{P}$ waves after opioid tranquillization is administered
(B) Occasional second-degree heart block after intravenous or intramuscular atropine
(C) Decrease in heart rate after sotalol administration
(D) Systolic blood pressure drop from $140 \mathrm{mmHg}$ to $130 \mathrm{mmHg}$ after diltiazem

